\title{
Synthesis and Characterization of Superparamagnetic $\mathrm{Fe}_{3} \mathrm{O}_{4} @ \mathrm{SiO}_{2}$ Nanoparticles
}

\author{
Sachnin A. Kulkarni*, P. S. Sawadh ${ }^{\dagger}$, and Prakash K. Palei \\ Department of CEES, MIT College of Engineering, Pune-411038, Maharashtra, India. \\ ${ }^{*}$ E-mail: kulkarnisachin42@gmail.com \\ ${ }^{\dagger}$ Department of Physics, B.D. College of Engineering, Sevagram- 442102, Maharashtra, India
}

(Received October 28, 2013; Accepted January 16, 2014)

\begin{abstract}
Magnetite nanoparticles were prepared by co-precipitation method and then silica was coated onto the surface of $\mathrm{Fe}_{3} \mathrm{O}_{4}$ by hydrolysis of TEOS. The silica coated magnetite nanoparticles were characterized for its structural, microstructural, optical, vibrational and magnetic properties by X-ray diffraction analysis, Scanning electron microscopy, UV-visible spectroscopy, Infrared spectroscopy and Vibration sample magnetometer, respectively. XRD study confirmed the presence of $\mathrm{SiO}_{2}$ on the surface of magnetite nanoparticles. SEM study indicated that with increase in TEOS content the particles become bigger and mono-disperse. It was also found that the silica coating prevents magnetic particles from aggregation and imparts excellent stability.
\end{abstract}

Key words: $\mathrm{Fe}_{3} \mathrm{O}_{4}$, Co-precipitation, Superparamagnetic, Aggregation

\section{INTRODUCTION}

Magnetite nanoparticles have received a great deal of attention because of their potential use in various biomedical applications, including contrast agents in magnetic resonance imaging (MRI), magnetic separation and sorting of cells and proteins, immunoassay in pathology laboratories, hyperthermia treatment for cancer tumors, controlled and targeted delivery of pharmaceuticals and therapeutic genes. ${ }^{1-10}$ Looking at the importance of magnetite nanoparticles, in recent years, much attention has been focused on the synthesis of uniformly sized magnetic nanoparticles. ${ }^{11-21}$

In spite of named benefits, there are some basic challenges in order to make magnetite nanoparticles suitable for various potential applications. One major problem associated with these nanoparticles (NPs) is that these are highly prone to aggregation because of their large specific surface area, high surface energy and high magnetization value. Therefore, they show poor dispersion in water as well as in organic solvents. Another problem with these NPs is that because of having $\mathrm{Fe}^{2+}$ ions, it oxidizes easily and is vulnerable to lose magnetism. Moreover, it is difficult to graft the surface of $\mathrm{Fe}_{3} \mathrm{O}_{4}$ NPs with organic materials since there are few hydroxyl groups present on their surface. ${ }^{22}$ In order to solve these problems, coating of magnetite nanoparticles surface with various inorganic materials such as noble metals, metal oxides and silica within core/ shell structures, has been suggested. Among these coating materials, silica has allocated a special place to itself because of its unique properties such as chemical stability, biocompatibility, strong affinity towards magnetite and reactivity with various coupling agents. ${ }^{23-28}$

There are many reports in the literature which are focused on the synthesis of agglomeration free magnetite-silica composite nanoparticles, but most of the report shows illdefined structure and morphology as a result of ignoring pretreatment of magnetite before coating with silica. ${ }^{29}$ Very few works have been directed to study systematically the formation of well-defined silica-coated magnetite nanoparticles using TEOS.

It has been reported that the structure and morphology of the resultant nanocomposites cannot be well controlled if the prepared magnetite NPs by co-precipitation method were used directly without any treatment as seeds. According to the reports of Wang et al. $\mathrm{Fe}_{3} \mathrm{O}_{4} \mathrm{NPs}$ coagulate during coating process which results in the formation of large aggregates of silica-coated magnetite NPs. ${ }^{30}$ Hence, the stabilization of magnetite NPs is necessary to enhance their dispersing stability in reaction media during the coating process prior to fabrication of the core/shell nanostructures. For this purpose, researchers have used various surfactants and stabilizers for surface modification of magnetic NPs during the synthesis process. This stability is based on creating electrostatic (due to ionic compounds) and steric (due to long-chain hydrocarbons) repulsion between NPs that can overcome the magnetic and surface-related attractions. ${ }^{31}$ 
Therefore, in this work, the silica-coated magnetite nanoparticles with different TEOS content have been synthesized by using a two step synthesis route. The magnetite nanoparticles are prepared by co-precipitation method. The as prepared magnetite nanoparticles are used to synthesize the $\mathrm{Fe}_{3} \mathrm{O}_{4} @ \mathrm{SiO}_{2}$ nanocomposite using modified Stöber method. Initially, ammonium hydroxide was used to stabilize magnetite NPs. The surface morphology of the NPs was captured to confirm the formation of uniform silica-coated magnetite particles with core-shell structure. The structural, microstructural, optical and magnetic properties were studied to extract more detail information about the nanocomposite.

\section{EXPERIMENTAL PROCEDURE}

\section{Materials}

For the synthesis of magnetic nanoparticles in this study, all chemicals were of analytical grade and were used without further purification. Ferric chloride hexa-hydrate $\left(\mathrm{FeCl}_{3} \cdot 6 \mathrm{H}_{2} \mathrm{O}\right)$, ferrous chloride tetra-hydrate $\left(\mathrm{FeCl}_{2} \cdot 4 \mathrm{H}_{2} \mathrm{O}\right)$, tetraethylorthosilicate (TEOS), and ammonium solution (26\% of ammonia) were purchased from Aldrich.

\section{Co-precipitation Method}

Ferric chloride and ferrous chloride were mixed in 2:1 molar ratio. The solutions of $\mathrm{Fe}^{2+}$ and $\mathrm{Fe}^{3+}$ were prepared by making their aqueous solutions in distilled water and this solution containing both ions was then heated up to $50{ }^{\circ} \mathrm{C}$ for $10 \mathrm{~min}$. After heating, the solution was precipitated by ammonia solution with continuous stirring on the magnetic stirrer at $50{ }^{\circ} \mathrm{C}$. Black colored particles of iron oxide were precipitated. These particles were then separated from the solution by using a strong magnet and then were washed many times with distilled water. The precipitated magnetite is black in color. The powder was then dried in hot air oven at $100{ }^{\circ} \mathrm{C}$ for overnight. The overall reaction can be written as

$$
\mathrm{Fe}^{2+}+2 \mathrm{Fe}^{3+}+8 \mathrm{OH}^{-} \rightarrow \mathrm{Fe}_{3} \mathrm{O}_{4}+4 \mathrm{H}_{2} \mathrm{O}
$$

\section{Preparation of $\mathrm{Fe}_{3} \mathrm{O}_{4} / \mathrm{SiO}_{2}$ Nanoparticles}

The $\mathrm{Fe}_{3} \mathrm{O}_{4}$ nanoparticles $(0.25 \mathrm{~g})$ were ultrasonicated for $1 \mathrm{~h}$ to make them uniformly disperse in anhydrous ethanol $(40 \mathrm{~mL})$. Concentrated ammonium hydroxide $(4.5 \mathrm{~mL})$ was diluted to the above solution, and TEOS $(1 \mathrm{~mL})$ was quickly added under vigorous stirring. The solution was left to stir for $12 \mathrm{~h}$. The product was collected by centrifugation and washed with anhydrous ethanol three times. Now further $\mathrm{Fe}_{3} \mathrm{O}_{4} / \mathrm{SiO}_{2}$ nanoparticles are synthesized at different TEOS volume of $1.5 \mathrm{~mL}$ and $2 \mathrm{~mL}$.

\section{Characterization}

The phase formation of $\mathrm{Fe}_{3} \mathrm{O}_{4} / \mathrm{SiO}_{2}$ nanoparticles were analyzed using X-ray powder diffraction (XRD, Brukeraxs, D8 Advance) over the $2 \theta$ ranges from $20-70^{\circ}$ at scan rate of $2 \% \mathrm{~min}$, using $\mathrm{Cu}-\mathrm{K}_{a}$ radiation $(1.5408 \mathrm{~A})$. The surface morphology of the samples was taken by using JEOL JSM 6480 LV scanning electron microscope (SEM). Fourier transform infrared (FTIR) spectra were obtained using Nicolet FTIR Avatar 360 (Nicolet, USA) with the $\mathrm{KBr}$ method. The Optical properties were studied by using UV CARY 100 Scan UV-visible Spectrophotometer. Magnetic properties (M-H curve) were measured with a vibrating sample magnetometer (VSM, Quantum Design) at room temperature.

\section{RESULTS AND DISCUSSION}

Fig. 1 shows the XRD patterns of pure and modified $\mathrm{Fe}_{3} \mathrm{O}_{4}$ nanoparticles. XRD peaks of pure magnetite sample are found to be sharp and distinct indicating good crystallinity and homogeneity of the sample. The absence of secondary peaks ensures the good purity of the sample. However, in the Si doped magnetite samples, with the increase in dopant concentration the intensity of the peaks are found to decrease which may be due to the amorphous nature of $\mathrm{Si}$. In case of doped samples a broad peak $\sim 25$ degree is observed which confirms the presence of $\mathrm{Si}$ in the sample. The SEM micrographs of the pure and modified $\mathrm{Fe}_{3} \mathrm{O}_{4}$ nanoparticles are shown in Fig. 2. It is found that with the increase in TEOS content clear and distinct spherical shaped particles are obtained. It can also be seen that the particle size is increased with the increase in TEOS content.

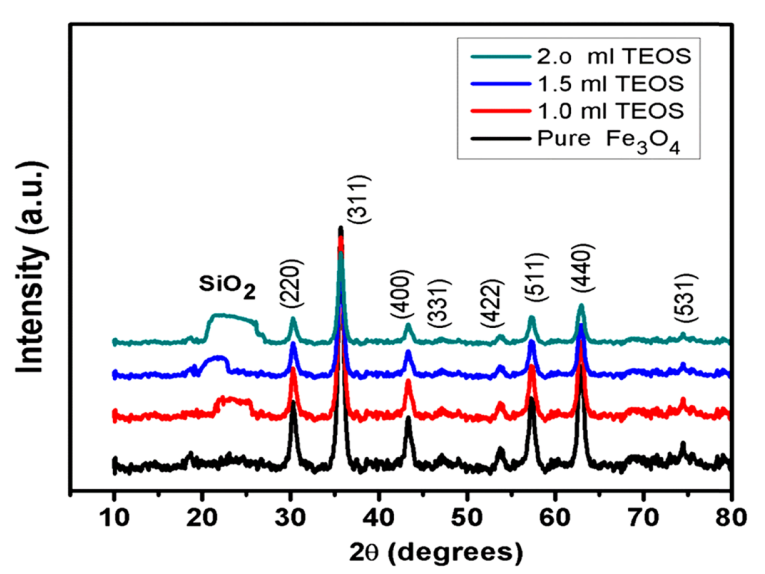

Figure 1. XRD pattern of pure and modified $\mathrm{Fe}_{3} \mathrm{O}_{4}$ nanoparticles. 


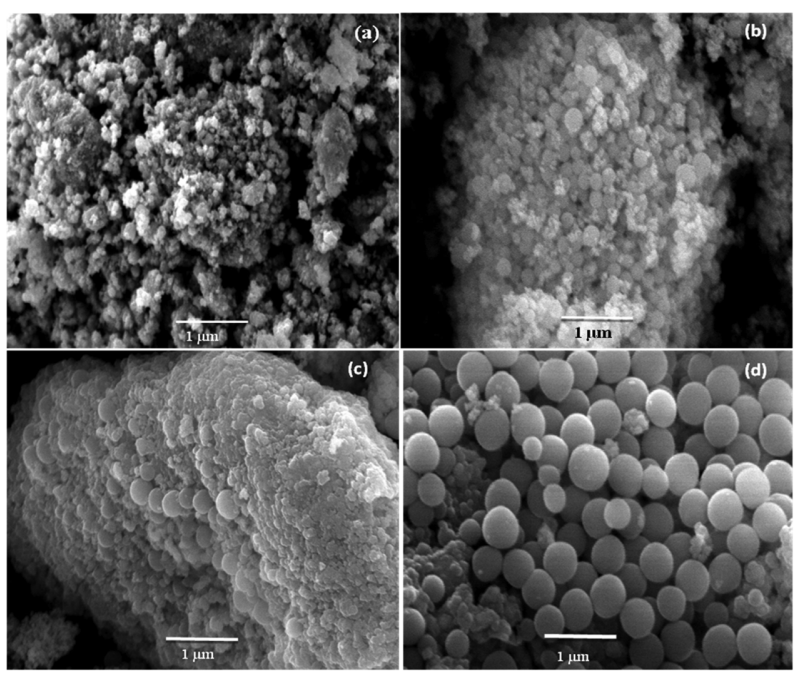

Figure 2. SEM micrographs of (a) pure $\mathrm{Fe}_{3} \mathrm{O}_{4}$ (b) $1 \mathrm{ml}$ TEOS (c) $1.5 \mathrm{ml}$ TEOS and (d) $2 \mathrm{ml}$ TEOS modified $\mathrm{Fe}_{3} \mathrm{O}_{4}$ nanoparticles.

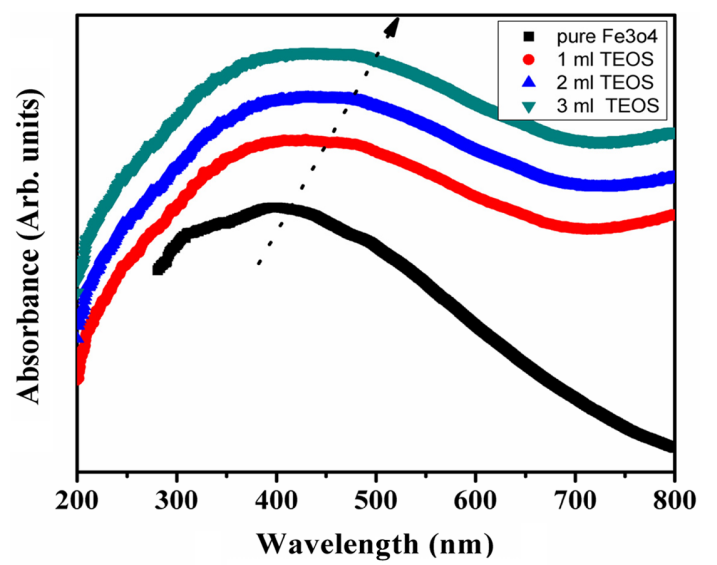

Figure 3. UV-vis Spectra of pure $\mathrm{Fe}_{3} \mathrm{O}_{4}$ and $\mathrm{Si}$ modified $\mathrm{Fe}_{3} \mathrm{O}_{4}$ nanoparticles.

The $\mathrm{Fe}_{3} \mathrm{O}_{4}$ nanoparticles are agglomerated seriously and the size is very small. But the composite nanoparticles are almost monodisperse with uniform size. It proves the dispersion of $\mathrm{Fe}_{3} \mathrm{O}_{4} @ \mathrm{SiO}_{2}$ composite nanoparticles is apparently improved.

To determine the optical properties of the synthesized $\mathrm{Fe}_{3} \mathrm{O}_{4} @ \mathrm{SiO}_{2}$ nanoparticles the UV-vis Spectra (with DRS) were collected and are shown in Fig. 3. It can be observed that with increase in TEOS content the absorption peak is shifted towards the higher wavelength side i.e. red shift is observed. It is a well known fact that with the increase in particle size the band gap of a material decreases which results in the shifting of the absorption peak towards the higher wavelength side. This phenomenon occurs, since in a nanomaterial the energy levels are discretely defined

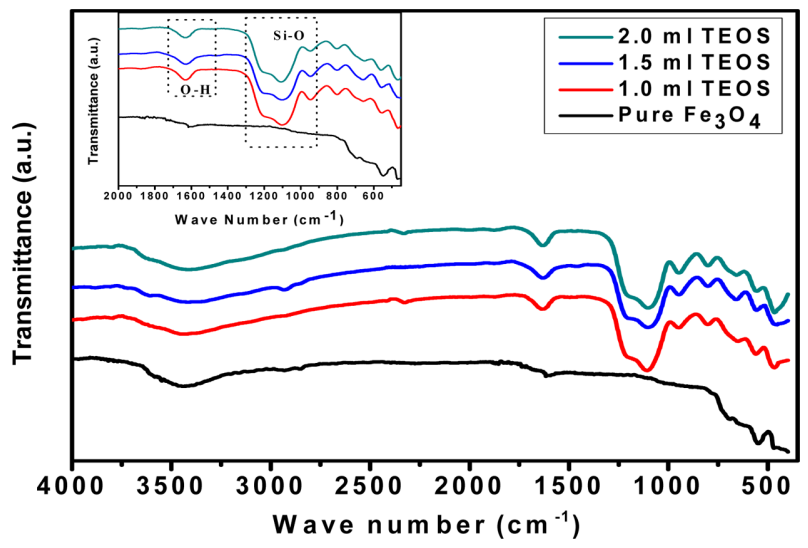

Figure 4. FTIR Spectra of pure $\mathrm{Fe}_{3} \mathrm{O}_{4}$ and $\mathrm{Si}$ modified $\mathrm{Fe}_{3} \mathrm{O}_{4}$ nanoparticles.

and the energy level shifts according to the quantum size effect (QSE) but when the size of the particle increases the energy levels are no more discrete which decreases the band gap of the material.

In the present study it is observed that with the increase in TEOS content in the composite, the particle size of the composite was found to increase and hence the band gap decreases.

Fig. 4 shows the FTIR patterns of pure and $\mathrm{SiO}_{2}$ modified $\mathrm{Fe}_{3} \mathrm{O}_{4}$ nanoparticles. In case of pure magnetite nanoparticles, the presence of vibrational stretching band at $\sim 570$ and $400 \mathrm{~cm}^{-1}$ are attributed to the $\mathrm{Fe}-\mathrm{O}$ bonding. With increase in TEOS concentration another band at $\sim 1100 \mathrm{~cm}^{-1}$ is observed. In the $\mathrm{SiO}_{2}$ modified magnetite nanoparticles the presence of peaks at $\sim 1100 \mathrm{~cm}^{-1}$ corresponds to the bending vibration of $\mathrm{Si}-\mathrm{O}$ bond. Along with $\mathrm{Si}-\mathrm{O}$ band another bands at $\sim 3400$ and $1630 \mathrm{~cm}^{-1}$ is also observed. The absorption bands near $\sim 3400$ and $1630 \mathrm{~cm}^{-1}$ is attributed to the absorbed water or $\mathrm{OH}^{-}$on the surface of sample. Inset of Fig. 4 shows expanded view of this region. This figure clearly indicates that for pure $\mathrm{Fe}_{3} \mathrm{O}_{4}$ nanoparticles $\mathrm{O}-\mathrm{H}$ or $\mathrm{Si}-\mathrm{O}$ bonds are absent which confirms the formation of phase pure magnetite nanoparticles. However, $\mathrm{O}-\mathrm{H}$ and $\mathrm{Si}-\mathrm{O}$ related bands are observed with incorporation of TEOS. This data supports the formation of $\mathrm{SiO}_{2}$ shell on $\mathrm{Fe}_{3} \mathrm{O}_{4}$ nanoparticles. It is evident here that with the Increase in TEOS content the strength of $\mathrm{Si}-\mathrm{O}$ bond increases.

Fig. 5 shows the magnetization vs. magnetic field loops of the pure and $\mathrm{SiO}_{2}$ modified $\mathrm{Fe}_{3} \mathrm{O}_{4}$ nanoparticles. Development of saturated loop confirms the magnetic nature of all the samples. The absence of hysteresis and remnant magnetization indicates that these particles are superpara- 


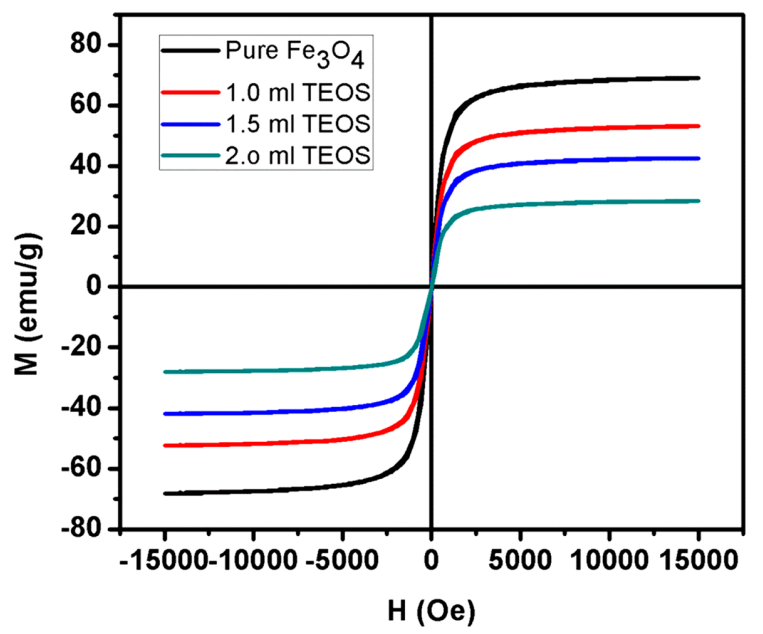

Figure 5. Magnetic hysteresis loop of pure and $\mathrm{Si}$ modified $\mathrm{Fe}_{3} \mathrm{O}_{4}$ nanoparticles.

magnetic in nature. ${ }^{32}$ The saturation magnetization $(\mathrm{Ms})$ is found to be strongly dependent on the particle size as well as TEOS content. The value of Ms (63.5) is found to be higher in case of pure $\mathrm{Fe}_{3} \mathrm{O}_{4}$ whereas with the increase in TEOS content it decreases. The decrease of Ms value with the increase of TEOS content in the composite can be attributed to the non-magnetic nature of $\mathrm{SiO}_{2}$ nanoparticles. The increase of the height of the $\mathrm{Si}-\mathrm{O}$ band in the FTIR pattern at $\sim 1100 \mathrm{~cm}^{-1}$ (Fig. 4) also supports this fact. The decrease of Ms value can also be explained in terms of the increase of particle size. The decrease in Ms value at smaller particles sizes is attributed to the noticeable surface effects in these nanoparticles. The surface of the nanoparticles is considered to be composed of some canted or disordered spins that prevent the core spins from aligning along the field direction resulting in decrease of the saturation magnetization of the small sized nanoparticles. ${ }^{33}$ Since all these samples show perfect superparamgnetic behavior, hence they are believed to be promising for wide range of engineering applications, such as drug delivery, bio-separation and magnetic resonance imaging.

\section{CONCLUSIONS}

$\mathrm{Fe}_{3} \mathrm{O}_{4}$ nanoparticles are prepared by chemical co-precipitation method. Then silica was coated onto the surface of $\mathrm{Fe}_{3} \mathrm{O}_{4}$ by hydrolysis of TEOS. XRD patterns confirm the presence of $\mathrm{SiO}_{2}$ phase along with the magnetite phase in the sample. UV-vis spectra shows a red shift with increase in $\mathrm{SiO}_{2}$ doping. This is due to the fact that with increase in particle size the band gap of the material decreases. The magnetization measurements confirm that the samples are super paramagnetic in nature. The saturation magnetization (Ms) was found to decrease drastically with increase in $\mathrm{SiO}_{2}$ coating.

Acknowledgments. Authors are thankful to the Executive Director, Dr. Mangesh T. Karad and Principal, Dr. V. M. Wadhai, MIT College of Engineering, Pune for the financial support and encouragement. And the publication cost of this paper was supported by the Korean Chemical Society.

\section{REFERENCES}

1. Chu, M.; Shao, Y.; Peng, J.; Dai, X.; Li, H.; Wu, Q.; Shi, D. Biomaterials 2013, 34, 4078.

2. Zhu, S.; Guo, J.; Dong, J.; Cui, Z.; Lu, T.; Zhu, C.; Zhang, D. Ultrasonics Sonochem. 2013, 20, 872.

3. Wei, X.; Liu, T.; Li, J.; Chen, X. Int. J. Electrochem. Sci. 2011, 6, 4953.

4. Ito, A.; Ino, K.; Kobayashi, T. Biomaterials 2005, 26, 61856193.

5. Uebe, R.; Henn, V.; Schüler, D. J. Bacteriol. 2012, 194, 1018-1023.

6. Chomoucka, J.; Drbohlavova, J.; Huska, D.; Adam, V. Kizek, R.; Hubalek, J. Pharmacol. Res. 2010, 62, 144-149.

7. Zhang, Z.; Wang, X.; Yang, X. Analyst. 2011, 136, 4960.

8. Xiong, C.; Yuan, X.-H.; Zhou, J.-D.; Chen, Y.; Chen, F.H.; Xin, Xu, L. Afr. J. Pharm. Pharacol. 2013, 7, 666.

9. Hu, F.; MacRenaris K.; Waters E.; Schultz-Sikma E.; Eckermann, A.; Meade, T. Chem. Commun. 2010, 46, 73-75.

10. Xiao, L.; et al. ACS Nano 2011, 5, 6315-6324.

11. Ataie, Kazemzadeh, H.; Nikkhah-Moshaie, R.; Ahmed, F.-M. IEEE Trans. Magn. 2009, 45.

12. ElGhandoor, H.; Zidan, H.-M., Khalil Mostafa, M. H.; Ismail, M.-I.-M. Int. J. Electrochem. Sci. 2012, 7, 5734.

13. Hai, H.-T.; Kura, H.; Takahashi, M.; Ogawa, T. J. Colloid Interface Sci. 2010, 341, 194.

14. Hua, Z.; Deng, Y.; Li, K.; Yang, S. Nanoscale Res. Lett. 2012, 7, 129.

15. Liu, X.; Guo, Y.; Wang, Y.; Ren, J.-W.; Wang, Y.; Guo, Y.; Guo, Y.; Lu, G.; Wang, Y.; Zhang, Z. J. Mater. Sci. 2010, 45, 906.

16. Mihoc, G.; Ianos, R.; Curariu, C.-P. J. Therm. Anal. Calorim. 2013, 112, 391.

17. Zhang, S.; Wu, W.; Xiao, X.; Zhou J.; Ren, F.; Jiang, C. Nanoscale Res. Lett. 2011, 6, 89.

18. Weia, Y.; Hanb, B.; Hua, X.; Linc, Y.; Wangd, X.; Denga, X. Procedia Eng. 2012, 27, 632-637.

19. Duan, L.-F.; Jia, S.-S.; Wang, T.-H.; Xue, B.; Wang, Y.-Q.; Zhao, L.-J. Met. Mater. Int. 2011, 17, 801.

20. Kazemzadeh, H. Int. J. Mod. Phys.: Conference Series 2012, 5, 160.

21. Srivastava, V.; Singh, P.-K.; Weng, C.-H.; Sharma, Y.-C. Pol. J. Chem. Technol. 2011, 13, 1.

22. Chin, S.-F.; Pang, S.-C.; Tan, C.-H. J. Mater. Environ. Sci. 
2011, 2, 299.

23. Zhu, Y.; Fang, Y.; Kaskel, S. J. Phys. Chem. C. 2010, 114, 16382.

24. Abid, A.-D.; Kanematsu, M.; Young, T.-M.; Kennedy, L.M. Aerosol Sci. Tech. 2013, 47, 169.

25. Chang, C.-C.; Zhao, L.; Wus, M. K. J. Appl. Phys. 2010, 108, 094105

26. Wang, L.; Sun, Y.; Wang, J.; Wang, J.; Yu, A.; Zhang, H.; Song, D. Colloids Surf., B. 2011, 84, 484.

27. Sun, W.; Sun, W.; Kessler, M.-R.; Bowler, N.; Dennis, K.W.; McCallum, R.-W.; Li, Q.; Tan, X. Appl. Mater. Interfaces 2013, 5, 1636.

28. Ahangaran, F.; Hassanzadeh, A.; Nouri, S. Int. Nano Lett.
2013, 3, 23.

29. Deng, Y.; Wang, C.; Hu, J.; Yang, W.; Fu, S. Colloids Surf., A. 2005, 262, 87-93.

30. Wang, H.; Nakamura, H.; Yao, Y.; Maeda, H.; Abe, E. Chem. Lett. 2001, 1, 1168.

31. Helmi Rashid Farimani, M.; Shahtahmasebi, N.; Rezaee Roknabadi, M.; Ghowsc, N.; Kazemi, A. Physica E 2013, 53, 207-216.

32. Kulkarni, S.-A.; Sawadh, P.-S.; Palei, P.-P.; Kokate, K.-K. Ceram. Int. 2014, 40, 1945-1949.

33. Maaz, K.; Karim, S.; Mumtaz, A.; Hasanain, S.-K.; Liu, J.; Duan, J.-L. J. Magn. Magn. Mater. 2009, 321, 1838-1842. 